\title{
Revista Eletrônica da ANPHLAC entrevista o historiador Pablo Yankelevich
}

Como parte deste dossiê comemorativo do centenário da Revolução Mexicana e da Constituição de 1917, apresentamos uma entrevista realizada com o historiador Pablo Yankelevich. Doutor em Estudos Latino-Americanos pela UNAM e atualmente professor de El Colegio de México, Yankelevich também foi investigador visitante de várias instituições mexicanas e estrangeiras.

Entre suas principais obras sobre o tema, destacamos La diplomacia imaginaria. Argentina y la Revolución Mexicana, 1910-1916 (1994); Miradas australes. Propaganda, cabildeo y proyección de la Revolución Mexicana en el Río de la Plata, 1910-1930 (1997) e La Revolución Mexicana en América Latina: intereses políticos e itinerarios intelectuales (2003).

As obras de Pablo Yankelevich sobre as projeções da Revolução Mexicana no Rio da Prata ocupam um lugar pioneiro dentro da historiografia que tem se ocupado em resgatar o impacto do processo revolucionário do México em outros cenários latinoamericanos. O estudo da temática remonta ao trabalho de Carlos Rama sobre o Uruguai, nos anos 50, mas os trabalhos de Yankelevich - juntamente com os de Ricardo Melgar Bao sobre as leituras andinas da Revolução - destacam-se por aprofundar os estudos a respeito do tema, rompendo com as tradicionais perspectivas nacionais das historiografias do continente e descortinando um instigante campo de estudos que, em grande medida, continua aberto a investigações.

Além das obras citadas sobre o assunto em foco, Yankelevich também coordenou diversas obras coletivas, principalmente sobre o tema do exílio latinoamericano no México, como En México, entre exilios. Una experiencia de sudamericanos (1997); México, país refugio. La experiencia de los exilios en el siglo XX (2001); Represión y destierro. Itinerarios del exilio argentino (2004); Exilios. Destinos y experiencias bajo la dictadura militar (junto con Silvina Jensen, 2007) y Nación y extranjería. La exclusión racial en las políticas migratorias de Argentina, Brasil, Cuba y México (2009).

\section{GANPHLAC}


REA: Para empezar, quisiéramos que usted hiciera una breve presentación de su trayectoria intelectual, de su formación académica y cómo ha llegado al tema de México.

PY: Nací en Argentina y llegué a México hace más de cuarenta años. Mis estudios universitarios los inicié en Argentina y no pude concluirlos. Se me atravesó el golpe de Estado de 1976 y debí abandonar el país. En México y en la UNAM concluí mis estudios de grado y posgrado en historia. Este tránsito entre los dos extremos América Latina ha tenido bastante que ver con mis preocupaciones sobre la recepción de la Revolución Mexicana en el continente. El tema apareció en parte por lecturas diversas en las que, sin mayores precisiones, se hacía referencia al impacto de la Revolución Mexicana y de la Revolución Rusa en la generación de la Reforma universitaria de 1918. Si se revisa la historiografía de la Reforma Universitaria se encontrará, casi como leitmotif, que lo sucedido en México y Rusia abrieron nuevos horizontes en el pensamiento y la acción de la juventud universitaria. Sobre la revolución rusa no era difícil seguir sus huellas, toda vez que la impronta de la III Internacional había cristalizado en organizaciones y en publicaciones más o menos conocidas. Sin embargo, no había mayor información sobre la Revolución Mexicana. Por otro lado, en los inicios de mi investigación, un asunto central fue el trabajo de Friedrich Katz que cristalizó en los dos volúmenes de La Guerra Secreta de México. Esta obra fue reveladora tanto por lo que muestra de la Revolución Mexicana, como por la manera de pensarla y estudiarla. Katz demuestra que en México revolucionario se dirimieron muchos conflictos, y entre ellos, se dirimieron poderosos conflictos interimperiales entre Estados Unidos, Inglaterra, Alemania, Francia y en menor medida Japón. Yo había cursado unos seminarios con Katz de paso por México, y quedé deslumbrado con sus clases y luego maravillado con ese libro. Fue entonces que me formulé ciertas preguntas en torno a las lecturas latinoamericanas de la Revolución Mexicana. Mientras tanto, trabajaba en otros asuntos, algunos de ellos vinculados a la historia centroamericana, pero hubo una investigación que realicé en Buenos Aires que me condujo de manera definitiva al tema del impacto de la Revolución Mexicana en América Latina. A mediados de los años ochenta, yo vivía en Buenos Aires y trabajada en un proyecto sobre la historia de la Universidad de Buenos Aires en la segunda mitad del siglo XX. Era un proyecto fundado en entrevistas de historia oral. Entre mis entrevistados había

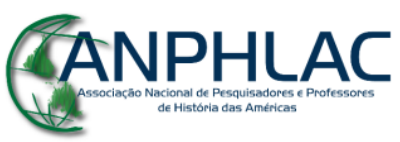

Revista Eletrônica da ANPHLAC, ISSN 1679-1061, №. 23, p. 174-184, Jul./Dez., 2017. http://revista.anphlac.org.br 
gente mayor, que en los años veinte y treinta del siglo pasado habían sido estudiantes universitarios y en algunos casos, dirigentes de organizaciones universitarias. Esos profesores me relataron el impacto que tuvo México en sus vidas y militancias. Fue entonces la memoria de mis entrevistados la que me condujo a la historia de la Revolución Mexicana en América Latina.

Hacia finales de los ochenta, algunas cuestiones comenzaron a ordenarse, por un lado, podía confirmar que por más imprecisas que fueran las referencias a México en la historiografía de la Reforma Universitaria, algo había pasado y podía ser contado; por otra parte, las enseñanzas del profesor Katz me animaron a pensar en que México había jugado un papel en América Latina, muy distinto al de las grandes potencias. La idea era muy sencilla, partí de la hipótesis de que la Revolución Mexicana no había pasado desapercibida en este continente, y propuse medir las intensidades del impacto de esa revolución. Por último, con avatares que no es este el lugar para relatar, pude encontrar el Archivo Histórico del Ministerio de Relaciones Exteriores de Argentina escondido en una enorme bodega en la periferia de la ciudad de Buenos Aires. Decidí iniciar una investigación, que en un principio se limitó al comportamiento diplomático de los países del ABC (Argentina, Brasil y Chile) en la mediación de Niagara Falls con motivo de la invasión norteamericana al Puerto de Veracruz en abril de 1914. Este episodio, había sido muy estudiado en México y en Estados Unidos, para empezar y solo por citar una obra, estaba la formidable investigación de Berta Ulloa (La Revolución intervenida), pero ninguno de estos trabajos había incorporado fuentes documentales sudamericanas. El primer resultado de esta indagatoria se convertiría en un pequeño libro que publiqué en 1994 (La diplomacia imaginaria. Argentina y la Revolución Mexicana) en donde muestro el papel que desempeñó México en la estrategia de una diplomacia argentina convencida de su capacidad de servir de contrapeso al imperialismo estadounidense. El libro fue muy bien recibido menos por la cancillería argentina. Sucedió que el libro fue publicado por la cancillería mexicana y según supe, la diplomacia del entonces presidente Menem, reclamó a México la publicación de una obra que exhibía más sombras que luces de lo que, para la historia diplomática argentina había sido una muestra de auténtica amistad con México. Sucede que para esa historiografía esta actuación del $\mathrm{ABC}$ se rescata como un ejemplo de desinteresada solidaridad. Los documentos que consulté mostraban lo contrario, y los testimonios de los diplomáticos

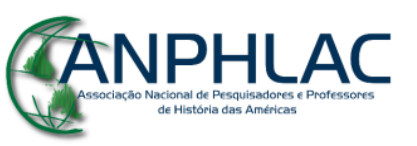

Revista Eletrônica da ANPHLAC, ISSN 1679-1061, №. 23, p. 174-184, Jul./Dez., 2017. http://revista.anphlac.org.br 
argentinos exhibían la soberbia y el racismo de una dirigencia argentina interesada en todo, menos en la suerte de México. Al margen de esta anécdota, lo importante fue que la fuente diplomática me llevó a la fuente hemerográfica y una vez allí, pude valorar la presencia de México en la opinión pública rioplatense. La investigación en periódicos y revistas reveló la magnitud del impacto de México revolucionario y me permitió delinear un proyecto de investigación más ambicioso que debía contemplar más temas, más actores y por supuesto más fuentes. Para empezar, las fuentes documentales de México, luego las norteamericanas junto a las de otros países de Sudamérica.

A inicios de los años noventa regresé a México, y comencé mi trabajo en archivos y bibliotecas, luego viajé a Estados Unidos, allí volví a encontrarme con el profesor Katz en la Universidad de Chicago. Mi investigación se benefició de un extraordinario diálogo y de sus estupendas recomendaciones extraídas de su profundo conocimiento de la historia latinoamericana y de una formidable intuición para advertir conexiones entre hechos, personajes, circunstancias y procesos históricos. La investigación avanzaba y lo hacía también por la ayuda de una buena cantidad de académicos. Señalaré solo algunos, el profesor Gregorio Weinberg en Argentina, uno de esos sabios que ha tenido ese país, y quien con toda generosidad puso su espléndida biblioteca a mi disposición, el profesor Sergio Bagú con quien tuve el privilegio de conversar muchas veces y de beneficiarme no solo de su inteligencia prodigiosa, sino también de su memoria, ya que por su propia trayectoria vital fue parte de la historia que trataba de reconstruir; el profesor mexicano Javier Garciadiego, sin duda, uno de los mayores historiadores de la Revolución Mexicana, y apasionado de la vida de personajes mexicanos que tuvieron una fuerza presencia en la vida cultural sudamericana. El profesor Ricardo Melgar Bao, él es el verdadero pionero en el asunto y en estos temas, sin cuyas enseñanzas, recomendaciones, y consejos no podría haber avanzado en mi investigación. En fin, son muchos y sería largo dar cuenta de todos, me limito a estos, porque valoro su ayuda como definitoria en el curso de mis investigaciones.

REA: Hace ya algunas décadas usted realizó trabajos pioneros en lo que toca a pensar la revolución mexicana en perspectiva continental, así que sus estudios pudieron romper con las configuraciones nacionales que hasta hoy enmarcan la

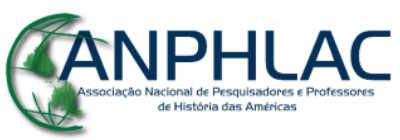

Revista Eletrônica da ANPHLAC, ISSN 1679-1061, №. 23, p. 174-184, Jul./Dez., 2017. http://revista.anphlac.org.br 
mayor parte de las historiografías latinoamericanas. ¿Podría hablar un poco de los desafíos que ha encontrado al realizar ese tipo de trabajo?

PY: Desde hace algunos años, y como eco de una reciente historiografía sobre todo norteamericana y en menor medida europea, se ha comenzado a hablar y a trabajar desde una perspectiva que se etiqueta como historia transnacional. ¿A que alude este asunto? Se trata de un esfuerzo por entender los procesos históricos como resultado de intercambios, conexiones, transferencias que atraviesan las fronteras nacionales. Es un llamado a romper el "provincianismo" que impone modos de hacer historias constreñidas a los límites físicos de las naciones y sobre todo a las relaciones entre esas fronteras y las de otras naciones. En este sentido, se puede hacer historia transnacional desde los más diversos asuntos y procesos, ya sean económicos, políticos o culturales. Yo creo que estas perspectivas son interesantes y sin lugar a dudas útiles, aunque hay que reconocer que la novedad que representan no es tan nueva. Mucha de la buena historia económica es transnacional, lo mismo en el campo de historia intelectual o de la historia política internacional, el problema es no perder vista que detrás de las acciones de empresas, empresarios, políticos, diplomáticos e intelectuales, hay voluntades de poder. Un poder que requiere órdenes jurídicos, económicos o políticos para afirmase, para consolidarse o para extenderse. Hay acciones de grupos, de clases, de elites que necesitan vínculos, relaciones e intercambios para existir y sobrevivir. Se trata de intereses que atraviesan fronteras nacionales muchas veces para fortalecerlas, para interconectarlas.

En relación a mi trabajo, no sé cuál etiqueta merecería, me refiero a si podría leerse desde horizontes trasnacionales, internacionales, políticos o intelectuales. Quizás haya algo de todo esto. Creo que la apuesta es a recuperar los encuentros, los contactos, los intercambios entre los revolucionarios mexicanos y sus interlocutores latinoamericanos, e intentar descubrir la cristalización de estos encuentros en acciones políticas concretas. Seguir las huellas de esos contactos obliga a trabajar en distintos escenarios: el diplomático, el literario, el sindical, el periodístico, etc. y obliga a descubrir las estrategias, las preocupaciones compartidas, las expectativas que despertó la revolución en México, y las enseñanzas que dejó esa revolución.

\section{CANPHLAC}


REA: Hay trabajos que abordan el tema de la Revolución Mexicana y los Estados Unidos y Europa. ¿Hay distinciones con relación a los abordajes latinoamericanistas? ¿Cómo ve usted estos estudios?

PY: La Revolución Mexicana y las principales potencias mundiales ha sido un campo muy estudiado, claramente el tema que ha concentrado la mayor atención ha sido la relación con Estados Unidos donde la historiografía es abundante, también hay trabajos muy importantes con relación a Gran Bretaña, Francia, y en menor medida Alemania. Es evidente la relevancia de estos estudios en función de los intereses económicos de estas potencias y la manera en que se articularon esos intereses en el contexto de la Primera Guerra Mundial. La relación de la Revolución con América Latina no admite comparación dada la escasa densidad de los vínculos económicos y también los de carácter político; sin embargo, esa relación existió y bien ha valido la pena explorarla. Esa exploración diría que es bastante desigual, en el terreno de la diplomacia, claramente hay un episodio, la intervención de los países del ABC en 1914 y luego en 1915. El hecho diplomático, por sí mismo requiere aún de una indagación en profundidad que conjunte y compare el comportamiento de Argentina, Brasil y Chile. Tenemos historiografías nacionales acerca de este episodio, aún no tenemos una indagación sobre la manera en que las tres diplomacias sudamericanas se articularon con la norteamericana y pretendieron incidir en el destino de México. Al margen del hecho diplomático, la intervención del $\mathrm{ABC}$ tuvo la virtud de instalar a la Revolución Mexicana en las opiniones públicas de los países latinoamericanos. La Revolución fue noticia y sobre ellas se reflexionó y en muchos casos se actuó. Aún hay mucho por indagar, se ha trabajado con seriedad con la prensa de Brasil, de Argentina y en menor medida de Colombia. Poco se sabe del resto. Hay estudios sobre vínculos entre México y unos pocos países latinoamericanos: Cuba, Argentina, Brasil, Colombia y Chile. Hay trabajos sobre México como territorio de refugio de perseguidos políticos, y en algunos casos de confabulaciones revolucionarias, diría que el caso más estudiado es el de los apristas peruanos en los años veinte; han aparecido indagaciones sobre exiliados centroamericanos y antillanos en los años cincuenta, y sobre los exilios sudamericanos de los años setenta. Comienzan a surgir estudios sobre vínculos intelectuales y producciones editoriales, el caso más relevante es el de la editorial Fondo de Cultura Económica en su proyección latinoamericana, se ha trabajado algunas personalidades

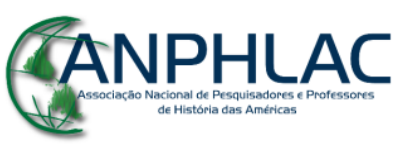

Revista Eletrônica da ANPHLAC, ISSN 1679-1061, №. 23, p. 174-184, Jul./Dez., 2017. http://revista.anphlac.org.br 
mexicanas, sin duda las figuras de Alfonso Reyes y José Vasconcelos han sido las más recurridas; sin embargo, hay muchas otras que están a la espera de indagaciones. Diría que la Revolución Mexicana en América Latina es todavía un campo en construcción.

REA: La historiografía de la Revolución de 1910 es casi un tema aparte dentro de la historia mexicana. Podría hablar de los trabajos que más llamaran su atención en los últimos años por su originalidad, abordaje o nuevas perspectivas sobre el tema.

PY: La Revolución Mexicana ocupa un ancho espacio en la historiografía mexicana, y esa historiografía ha producido en las últimas décadas obras de referencia que han marcado las formas de acercarse a esta historia. Ya hice referencia a las aportaciones de Friedrich Katz, habría que agregar su última gran obra, la biografía de Pancho Villa, a mi modo de ver, esfuerzo ejemplar en tanto reconstrucción de la historia del México revolucionario a través de la vida de uno de sus más emblemáticos caudillos. En el ámbito de las biografías históricas, rescato los más recientes aportes de Javier Garciadiego (Cultura y política en el México posrevolucionario. México, INEHRM, 2006; Rudos contra científicos: La Universidad Nacional durante la Revolución mexicana. México: COLMEX-UNAM, 1996; entre outros), en torno a un ancho elenco de figuras políticas e intelectuales de México revolucionario y contrarrevolucionario. En el mismo sentido, el reciente libro de Claudio Lomnitz sobre Ricardo Flores Magón [The return of comrade Ricardo Flores Magón. Nova York, Zone Books, 2014; El regreso del camarada Ricardo Flores Magón. México: Editorial Era, 2016]. Por otro lado, subrayo la ancha obra dispersa de Alan Knight, recientemente compilada y publicada por El Colegio de México en dos gruesos volúmenes [Repensar la Revolución Mexicana. Obra publicada em 2013]. Se tratan de brillantes ensayos de historia política sobre diferentes asuntos de la historia de México en la primera mitad del siglo pasado. Agregaría las investigaciones de Emilio Kourí sobre historia agraria [A Pueblo Divided: Business, Property, and Community in Papantla, Mexico. Stanford University Press, 2004; Un pueblo dividido: Comercio, propiedad y comunidad en Papantla, México: FCE; COLMEX, 2013], los trabajos de Mauricio Tenorio [Mexico at the World's Fairs: Crafting a Modern Nation. University of California Press, 1996; Artilugio de la nación moderna: México en las exposiciones universales, 1880-1930. México: FCE, 1998; El

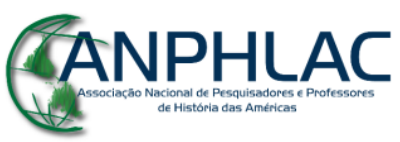

Revista Eletrônica da ANPHLAC, ISSN 1679-1061, №. 23, p. 174-184, Jul./Dez., 2017. http://revista.anphlac.org.br 
porfiriato. México: FCE, 2006, em coautoria com Aurora Gómez Galvarriat], los de Mary Kay [The Eagle and the Virgin: Nation and Cultural Revolution in Mexico, 19201940. Duke University Press, 2006; Cultural Politics in Revolution: Teachers, Peasants, and Schools in Mexico, 1930-1940. University of Arizona Press, 1997; La política cultural en la Revolución: Maestros, campesinos y escuelas en México, 1930-1940. México: FCE, 2001; entre outros] y Gilbert Joseph [Revolution from without: Yucatan, Mexico, and The United States, 1880-1924, New York: Cambridge University Press, 1982; The Mexico Reader: History, Culture, Politics. Duke University Press, 2003; entre outros] sobre la historia cultural, historia urbana, historia de las representaciones de México en el extranjero. Sobre la historia militar, Pedro Salmerón ha hecho aportes significativos tanto en lo referente a los ejércitos villistas como a los constitucionalistas [La División del Norte: la tierra, los hombres y la historia de un ejército del pueblo. México: Planeta, 2006; Los carrancistas: la historia nunca contada del victorioso Ejército del Noreste. México: Planeta, 2010; entre outros]. En el terreno de la historia empresarial y del trabajo industrial, destaco las investigaciones de Aurora Gómez [Industria y revolución. Cambio económico y social en el valle de Orizaba, México. México, FCE, 2016]. A su vez Pablo Picatto ha trabajado historia del crimen y el honor los años finales del porfiriato [City of Suspects: Crime in Mexico City, 1900-1931. Duke University Press, 2001], Elisa Speckman ha hecho aportes sustanciales a la historia jurídica en el México posrevolucionario [Crimen y castigo: legislación penal, interpretaciones de la criminalidad y administración de justicia, Ciudad de México, 1872-1910. México: COLMEX; UNAM, 2002; Población y sociedad: México (18801930). México: Taurus, 2015]; Claudia Agostoni sobresale por sus aportes a la historia de la salud pública [Médicos, campañas y vacunas: la viruela y la cultura de su prevención en México, 1870-1952. México: UNAM; Instituto Mora, 2016; entre outros]; Ricardo Pérez Montfort acaba de publicar un magnifico estudio sobre drogas y drogadicción [Tolerancia y Prohibición: aproximaciones a la historia social y cultural de las drogas en México 1840-1940. México: Penguin Random House Grupo Editorial, 2016]; Gabriela Cano [Sufragio femenino en el México posrevolucionario. In: GALEANA, Patricia et al. La Revolución de las mujeres en México. México: INEHRM, 2014] ha abierto espacios muy importantes para el abordaje de la historia de Revolución desde una perspectiva de género, en el terreno de la política exterior y las relaciones con

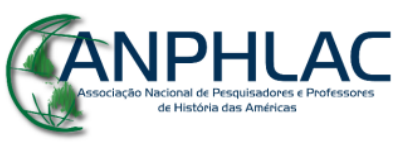

Revista Eletrônica da ANPHLAC, ISSN 1679-1061, №. 23, p. 174-184, Jul./Dez., 2017. http://revista.anphlac.org.br 
América Latina subrayo el reciente libro de Amelia Kiddle [Mexico's Relations with Latin America During the Cárdenas Era. University of New Mexico Press, 2016], sobre la política de Lázaro Cárdenas en América Latina. Podría continuar, y con toda seguridad el listado sería amplio y posiblemente incompleto. Lo sustancial es la vitalidad de la historiografía, su constante renovación y apertura a nuevos temas y perspectivas.

\section{REA: Hace pocos años fue conmemorado el centenario de la Revolución y en 2017 se celebra el centenario de la Constitución. ¿Cómo interpreta usted estas celebraciones?}

PY: Se ha escrito mucho sobre esta celebración que en el caso mexicano fue doble: doscientos años de la Independencia (1810) y cien años de la Revolución (1910). Solo quisiera marcar una circunstancia que de alguna manera muestra la importancia que aún tiene la Revolución no solo como hecho histórico que inauguró el siglo XX mexicano sino y sobre todo por la manera en que moldeó segmentos de la identidad nacional mexicana. La celebración del Centenario, me refiero a los eventos, actos y ceremonias oficiales correspondió a un gobierno presidido por el Partido de Acción Nacional. Un partido que en su origen (1939) se constituyó contra esa Revolución. Un partido católico, simpatizante del fascismo, admirador de Francisco Franco, un partido que aglutinó al conservadurismo de las clases medias atemorizadas por los perfiles radicales que Lázaro Cárdenas imprimió al proceso revolucionario. Nada más incómodo a los orígenes de ese Partido que celebrar la Revolución. Sin embargo, debieron hacerlo y los panistas encontraron en la figura de Francisco Madero, el presidente mártir fusilado en 1913, al héroe en quien depositaron convicciones y promesas de construir una sociedad más democrática.

La Revolución Mexicana es la única revolución del siglo XX, exceptuando a Corea de Norte y a Cuba, que no ha dejado de ser fuente de inspiración y legitimación política. Esa Revolución caló tan hondo en la imaginería nacional que resulta impensable imaginar políticas tendientes a desmontar un relato que reitera una y otra vez la legitimidad de los reclamos populares y la popularidad de sus líderes: Emiliano Zapata y Francisco Villa. Como tampoco es posible imaginar el desmontaje de un relato que muestra el esfuerzo de reconstrucción encabezado por Venustiano Carranza, Álvaro

\section{GANPHLAC}


Obregón, Plutarco Elías Calles y Lázaro Cárdenas. Muy poco se conserva de aquellas políticas, al contrario, los aires de modernización política y económica, en buena medida ubican el origen de los males que aquejan a México en aquellas políticas. En realidad, nada de esto tiene que ver con el quehacer historiográfico. Se trata en cambio de los usos políticos de la historia. En este sentido, llama la atención que la Revolución Mexicana continúa siendo un ancla identitaria que permite fijar proyectos políticos sobre todo en los partidos políticos de izquierda mexicana, mientras que los otros, incluyendo el propio PRI, no puede renunciar a ella, básicamente porque no tiene otro santoral cívico al que sujetarse.

\section{REA: La Revolución Mexicana aún es un marco para México? ¿Y para América Latina en términos políticos e historiográficos?}

PY: La relación de México con América Latina es inversamente proporcional a la relación de México con Estados Unidos. El papel que desempeña Estados Unidos es de tal magnitud que sólo cuando esas relaciones se enturbian, México vuelve el rostro a América Latina para activar políticas concretas. Eso sucedió cuando la Revolución Mexicana, y en buena medida eso explica el impacto que esa Revolución tuvo en la región. Fueron los mexicanos quienes se lanzaron hacia América Latina buscando solidaridad y la encontraron. Esto no significa que una vez estabilizada la relación con Estados Unidos desapareció el vínculo de México con América Latina. El vínculo permaneció, pero con una menor intensidad, se mantuvo vivo, se alimentó, pero fue menos potente.

Mucho se ha escrito sobre la naturaleza de la relación con Estados Unidos, y sobre la autonomía relativa que México logró mantener frente a los dictados imperiales sobre todo en el periodo de la Guerra Fría. Esa relativa autonomía encontró maneras muy eficaces de manifestarse cuando la Revolución Cubana. El asunto es entender a esa política exterior de México como uno de los dispositivos que permitió al régimen gobernar durante más de siete décadas. Esa política exterior se articulaba, de manera contradictoria, pero se articulaba al fin, con un sistema de partido único que cancelaba derechos ciudadanos que la propia política exterior defendía en el escenario internacional. Y esa política exterior fue una extraordinaria correa de trasmisión de ideas y de proyectos que acrecentaban la imagen de un México transformado por la vía

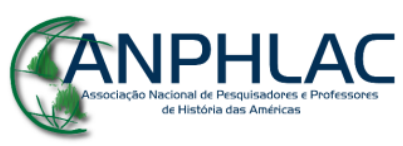

Revista Eletrônica da ANPHLAC, ISSN 1679-1061, №. 23, p. 174-184, Jul./Dez., 2017. http://revista.anphlac.org.br 
de una Revolución. Es importante tener en cuenta que por esa política exterior transitaron muchos políticos y también muy destacados intelectuales, fueron ellos, a manera de soldados culturales, quienes instalaron firmemente las imágenes de una Revolución que se hizo en el extremo norte del continente, que desafió la voluntad norteamericana, y que consagró en un texto constitucional (1917) todo un programa revolucionario que muy pronto se convirtió en un modelo para el pensamiento y la acción del progresismo latinoamericano.

La Revolución Mexicana concluyó hace muchas décadas. Fue un hecho que transformó de raíz a ese país y que tuvo un inmenso impacto fuera las fronteras nacionales. Para unos, esa revolución encendió alarmas sobre los peligros que encerraban órdenes políticos brutalmente excluyentes; para otros, esa la Revolución fue una llamarada de esperanzas en la posibilidad de concretar nuevas formas de organización política y social. México llamó la atención, concitó expectativas, generó conflictos internacionales, despertó solidaridades, alentó polémicas. En resumen, la Revolución no pasó desapercibida en América Latina, si bien algo ya sabemos, aún quedan una diversidad de asuntos por explorar.

\section{GANPHLAC}

